\title{
Regional features of the formation of sustainable tourist buildings of the Russian- Kazakhstan border
}

\author{
Svetlana Ilvitskaya ${ }^{1}$, Olga Bantserova $^{2}$, and Adema Kasimova ${ }^{2, *}$ \\ ${ }^{1}$ State University of Land Management, 15, Kazakova str., 105064, Moscow, Russia \\ ${ }^{2}$ Moscow State University of Civil Engineering (National Research University), 26, Yaroslavskoe \\ highway, 129337, Moscow, Russia
}

\begin{abstract}
The purpose of this research is to study climatic and landscape characteristics of the Russian-Kazakh border region on the example of the Astrakhan region, affecting the formation of sustainable "green" buildings of ethno-cultural tourist clusters. In the course of the study, it was concluded that in order to reduce the influence of severe climatic factors of the region, to create comfortable environmental conditions and the microclimate of the premises, it is necessary to use landscaping of horizontal and vertical structural elements of the cluster building complex. The work carefully examined various types of vertical and horizontal landscaping (extensive and intensive). Based on the analysis of scientific research and expeditions to the region, the condition of existing green spaces in Astrakhan was carefully studied. Thus, as a result of the study, certain types of plants were identified and recommended for the technology of horizontal gardening of ethno-cultural tourist clusters in the Astrakhan region.
\end{abstract}

\section{Introduction}

The Russian-Kazakh border region, which is part of the Eurasian space, is a territory with a rich historical and cultural heritage with numerous objects of tourist interest. The cultural heritage of this region is of great importance for the formation and development of ethnocultural tourism. Ethnocultural tourism is associated with the exchange of cultural traditions. An important role in culture formation of the people is played by the environment, its natural and climatic features and landscape characteristics of the area. At present, it is becoming increasingly difficult for nature to resist human activities. One way out is the use of renewable, non-waste energy sources. In this regard, one of the main trends in the development of cities associated with the concept of eco-architecture or "green" architecture, of which the landscape organization of the territory is an integral part, can be distinguished. Landscape architecture today has been enriched with new technologies: green roofs, green walls, buildings - artificial reliefs, the landscape inside the buildings.

\footnotetext{
*Corresponding author : adema-23352@inbox.ru
} 
When designing architectural objects in various regions of Russia, it is necessary to take into account the specifics of human interaction with the environment.

The composition of the regions of the Russian-Kazakhstan border includes Astrakhan, Volgograd, Saratov, Samara, Orenburg, West Kazakhstan, Aktobe and Atyraus. For further research, the Astrakhan region was chosen. A sharply continental and arid type of climate is observed in the region, characterized by cold winters and hot summers with dry winds (Fig. 1). The average air temperature in January in the region fluctuates around $-10 \mathrm{C} 0$, however, in the south of the region it can reach $-6 \mathrm{C} 0$, and in July it is $+25 \mathrm{C} 0$ throughout the territory. The relative annual humidity is $71 \%$, and the average annual wind speed in the region is $2.89 \mathrm{~m} / \mathrm{s}$. Precipitation in the region is unevenly distributed and is measured in the range of $245 \mathrm{~mm}$ in the north and $175 \mathrm{~mm}$ in the south. The region belongs to the 5 th zone of the total annual solar radiation on a horizontal surface under conditions of actual cloudiness equal to St. $1200 \mathrm{~kW} \bullet \mathrm{h} / \mathrm{m}$ [1]. The region is located on the Caspian lowland, the territory is mostly flat with high sand ridges and many channels in the Volga-Akhtuba floodplain and the Volga river delta. Also in the region there are a large number of salt lakes - Baskunchak, Tinaki, fresh lakes and ilmeni - Big Beshkul and Karabulak, Chichin and others [2]. Taking into account the natural-climatic and landscape features of the region will allow creating objects of ethnocultural tourism that correspond to the concept of sustainable tourism development and the principles of sustainable development in general, an integral part of which is eco-architecture.
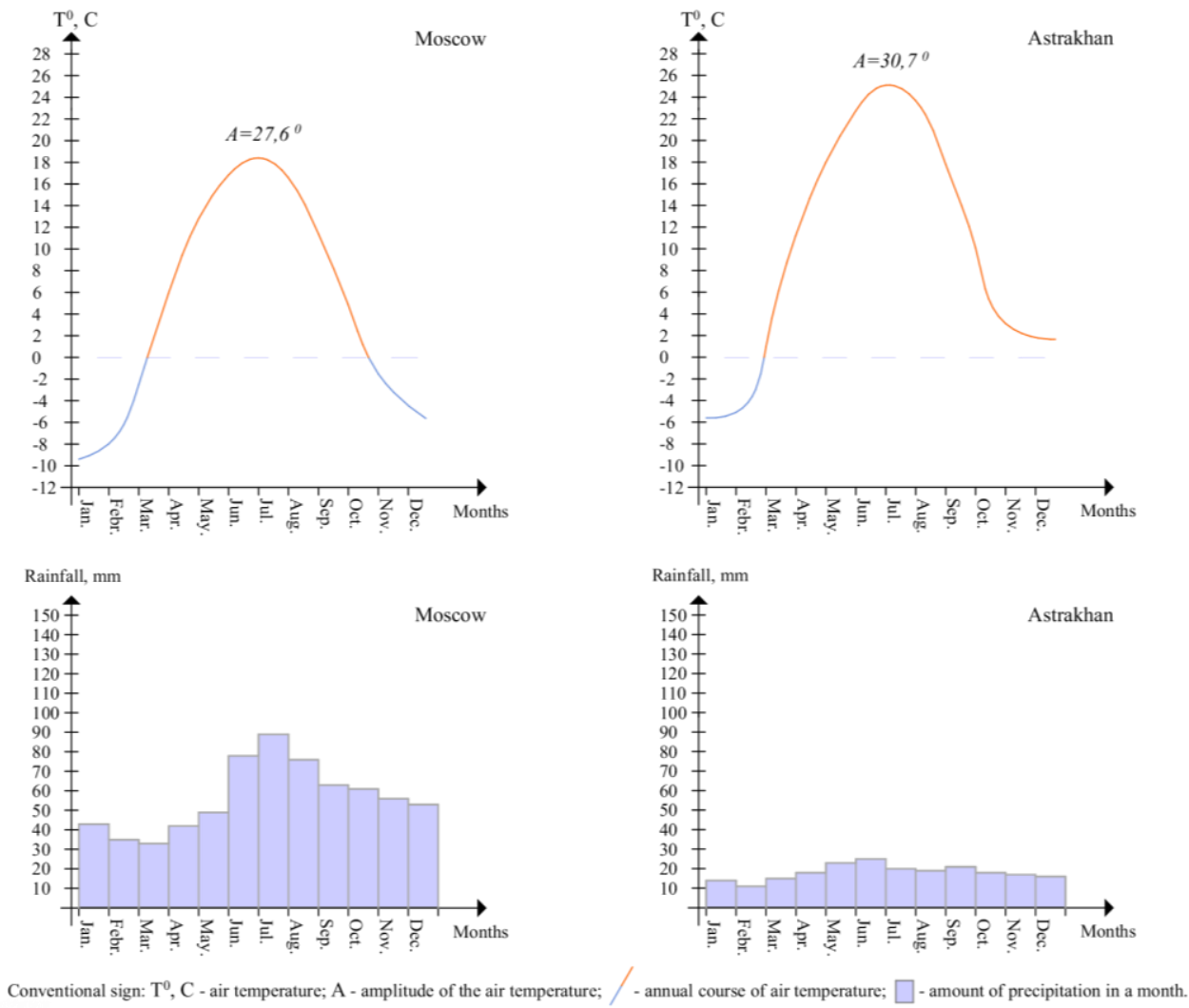

Conventional sign: $\mathrm{T}^{0}, \mathrm{C}$ - air temperature; A - amplitude of the air temperature; / - annual course of air temperature; $\square$ - amount of precipitation in a month.

Fig. 1. Comparative climate characteristics of the Moscow and Astrakhan regions of the Russian Federation. 


\section{Literature review}

Sustainable architecture is widely dealt with by architects Yu.A. Tabunshchikov, A.N. Tetior, S.V. Ilvitskay, O.L. Bantserova [3,4,5,6,7,8]. The technological principles of the selection of plants, as well as the features of landscaping, both in the European part of Russia and in the southern regions of the country, are occupied by scientific botanists and agronomists N.P. Kartashova, E.N. Eliseeva, M.S. Osintseva et al., as well as specialists from Zinco [9, 10, 11].

\section{Materials and methods}

The main research methods are field observations, photo fixation of existing objects in the studied territories, the study of natural and climatic features, landscape characteristics of the terrain, a comparative analysis of historically developed plant species common in the Astrakhan region and in other regions of Russia and Kazakhstan.

\section{Study results}

The problem of preserving the landscape, social and environmental identity of the territory under consideration, as well as the creation of ethnocultural tourism objects on its territory that comply with the principles of sustainable architecture, is relevant. At the Symposium on sustainable architecture in 2011, RAASN academician G.V.Esaulov was proposed the definition of sustainable architecture (sustainable architecture) as an architecture aimed at the consistent unity of socio-economic, engineering and technological, natural and environmental and aesthetic requirements based on the principles of sustainable development. At the same time, researchers O.E. Salmina and T.Yu. Bystrova highlighted the basic requirements that determine the nature of decisions in the field of sustainable architecture. Among these requirements, the most interesting are the principle of energy efficiency and improvement of urbanized environment through the use of modern technologies. These requirements are consistent with the Concept of sustainable tourism development, adopted in 2004 and aimed at protecting the environment, economic and socio-cultural aspects of tourism development $[12,13]$.

It is supposed to place tourist clusters as objects of ethnocultural tourism in the territory of the Astrakhan region. The ethnocultural tourism cluster is understood as a complex of buildings, structures, exhibition and landscape-recreational spaces with the appropriate infrastructure and ethnic groups associated with the existing cultural heritage [14]. Ethnocultural tourist clusters are supposed to be located in small and large cities of the region close to objects of tourist interest. One of such cities is the city of Kharabali, located $142 \mathrm{~km}$ from the city of Astrakhan, where the ruins of Saray-Batu, the former capital of the Golden Horde, an archaeological site of the 13th century, are located.

As previously discussed, the climatic and landscape conditions of the region are quite severe. When designing and building ethnocultural tourist clusters, it is necessary to reduce the impact of negative climatic factors, therefore, as part of the creation of eco-architecture, it is proposed to use horizontal and vertical landscaping of the cluster of buildings [15].

In ancient times, people built gardens on terraces and roofs, so one of the famous was the hanging gardens of Babylon. During the Renaissance in Italy, hanging gardens found new life in green theaters - architectural and landscape complexes that have a stage on several levels with various entrances hiding behind trimmed hedges. For decades, the roofs of wooden houses were covered with reeds, palm branches and straw, and in some cases they were strengthened with a layer of earth, on which grass subsequently grew. A new 
round of the idea of landscaping roofs is being developed in the 20th century in the works of architects such as Le Corbusier, F.L. Wright, W. Gropius et al. [16, 17].

Landscaping of buildings is divided into vertical and horizontal. Horizontal landscaping is the landscaping of horizontal or slightly sloping surfaces of structures covering, which can be various flat surfaces - roofs, peaks, etc. In vertical landscaping, the facades of buildings, their blind end walls, loggias, balconies, supporting walls and foundations serve as a support for plants. Today, there are many examples of "green buildings", both in Russian and in foreign practice. Some of the most famous foreign examples are the Osaka shopping center and the «Acros» cultural center in Japan, the Green Quarter in Milan, the Museum of Modern Art in New York, the IOC Swiss headquarters building, and others. At present, in Russia you can bring the following objects as examples: the roof of the sports and fitness complex in Yekaterinburg, the roof of the Union of Architects in Moscow, the roof of the greenhouse complex in the Botanical Garden of Moscow State University in Moscow, the Gazprom building complex in Moscow, the Rosmarin residential complex, etc. [18].

Among the main advantages of landscaping buildings are the following:

- change in the composition and quality of the atmosphere of the city;

- biodiversity of the urban environment due to the creation of an attractive habitat for insects and birds;

- aesthetic perception and psychological beneficial effect of gardening on the townspeople;

- the use of landscaping as a means of noise protection and sound insulation of the interior of the building;

- the use of landscaping as a sun protection device [19].

Thus, the landscaping device will reduce the level of energy consumption of the building and heat loss through the building envelope, increase its thermal insulation, provide sun protection and cooling due to evaporation of moisture and reduce wind speed and will help create a favorable indoor microclimate.

Vertical landscaping is divided into groups: continuous vertical landscaping, landscaping by a group of plants, Patrick Blanc's Vertical Garden Technology and container landscaping.

Continuous vertical and landscaping by a group of plants is a natural type of landscaping in which climbing plants and creepers are used, fixed with racks and garters on a vertical surface. Vast experience of application and a wide variety of plant assortment is a plus of this landscaping. The disadvantage of the system is the huge weight of these structures, constant monitoring of the life of the green mass and the destruction of building structures due to root sprouting. This landscaping is used to design unattractive facades with a relatively even breakdown into piers and window openings to give vividness to the facade [20].

The vertical gardens of Patrick Blanc are simple in design. Two layers of polyamide felt are mounted on the metal frame, serving as a plant substrate for the roots. For normal life, plants do not need land, because using the drip irrigation system, they feed on mineral solutions, and oxygen is taken from the air. A feature of the Blanc's method is that plants are planted on a substrate in the form of plant seeds (about 30 seeds per sq. M.), which are initially adapted to vertical living conditions and do not need to go through an adaptation period. The advantage of using this system is the ability to create live pictures from multicolored herbaceous plants of various species and color, and the minuses are the high cost of landscaping, the complexity of operation and the long growth time of the green mass of young plants [21].

Container landscaping involves the use of modules in which plants are planted. Hanging planters, wall containers, balcony drawers, pots, tubs and flowerpots can be used 
as modules. This landscaping is characterized by ease of installation, ease of changing the exposure, the use of modules with various substrates, a combination of plants with different soil requirements and the dismantling of the green wall in the winter. At the same time, it has several disadvantages - this is the complexity of the irrigation system, high operating costs and additional weight transferred to the supporting frame of buildings [20].

Horizontal landscaping of coatings is extensive (unattended) and intensive (with mandatory care). Greening of flat roofs is carried out both by an extensive and an intensive type, pitched roofs - only by an extensive one.

The extensive roof is an autonomous ecosystem that requires minimal human intervention (Fig. 2). This structure is a continuous carpet of low-growing drought-resistant plants. Crops are planted in a layer of earth laid on the roof with a thickness of 0.07 to 0.15 $\mathrm{m}$ or in various containers - pallets, pots. Plant care consists in intensive watering during crop growth. Depending on the functional features of the projected object, the composition of the roofing cake varies, however, in the general case, this technology involves the creation of the following layers: 1) An anti-root membrane that protects the waterproofing from plant roots; 2) A moisture-absorbing mat that retains moisture and nutrients in the system; 3 A drainage layer that creates the optimum moisture level in the roofing cake and provides air access to the roots of plants); 4) A system filter that prevents leaching of substances and does not allow small particles of soil to drain; 5) A nutrient substrate saturated with a sufficient amount of useful trace elements for plant growth with little or no human involvement; 6) The plant layer [9]. The advantage of extensive landscaping is the ease of installation and low cost, but the disadvantages are the limitations when creating landscape plant compositions and the inability to walk on this roof, which makes maintenance difficult. This landscaping is widely used in the arrangement of the green roof on residential buildings, roofs of garages and outbuildings.

An intensive roof is a structure whose thickness varies depending on the choice of plants: grass and brightly flowering crops need about $0.2-0.6 \mathrm{~m}$ of land, while growing shrubs and miniature trees, the fertile layer should be $0.7-1,2 \mathrm{~m}$. Plants are planted in the soil or piece containers (Fig. 2). The composition of the roofing cake for intensive gardening includes the following elements: 1) An anti-root film that does not allow the roots of plants, bushes and trees to damage the waterproofing materials of the roof; 2) A moisture-absorbing mat that holds nutrients and moisture, and also prevents mechanical damage of the root film; 3) A drainage system that maintains the necessary moisture level in the system, ventilates the roots of plants and removes excess moisture; 4) A filtration system that does not allow drainage to become clogged with particles of soil substrate, as well as preventing the leaching of nutrients; 5) A nutrient substrate saturated with the previously mentioned nutrients, letting air through and providing a comfortable vital activity of plants; 6) Plants [9]. The advantage of intensive landscaping is the ability to create a unique landscape and recreation. The disadvantage of this system is the massiveness of this design, the need for continuous maintenance and monitoring. 
a

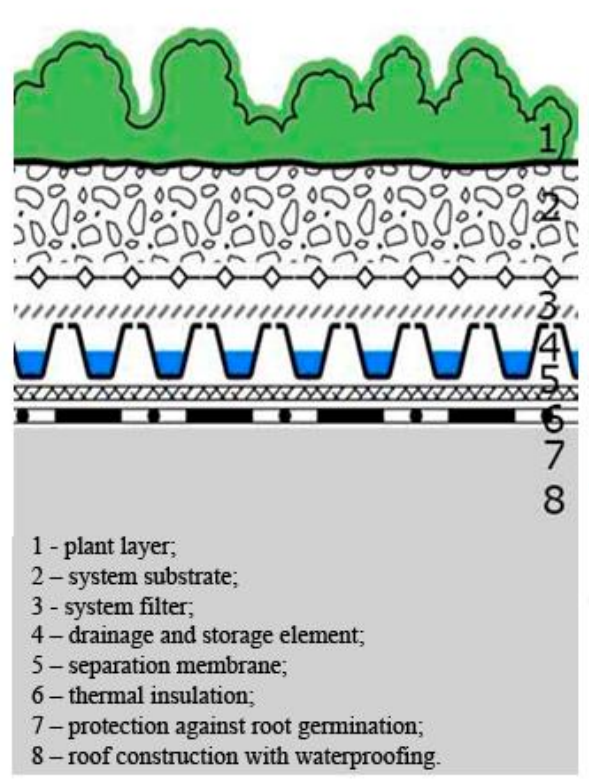

$\mathrm{b}$

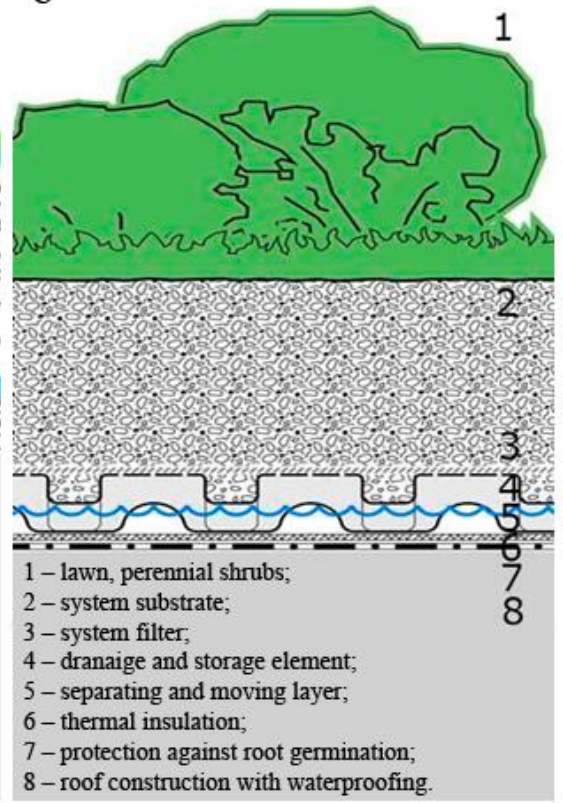

Fig. 2. Roofing pies of the extensive and intensive system of horizontal landscaping of ZinCo coatings: $\mathrm{a}-$ «Sedum carpet»; $\mathrm{b}-$ «Roof Garden».

One of the leading companies engaged in landscaping walls and coatings in Russia are ZinCo and Dörken. Specialists of these companies developed the following systems: for extensive landscaping - "Sedum carpet", "Grass lawn", "Roof without slope", "Rock garden", "Urban climate roofs"; for intensive gardening - "Fragrant grasses", "Landscape above the parking lot", "Summer meadow", "Farms on city roofs", "Roof garden" and Ecoroof "Natureline" and others [9]. With extensive landscaping of buildings, a low lawn or perennials with a bulbous root system is formed, mosses, succulents and other plants that do not require special care and are resistant to frost, wind and heat are also used. On average, when calculating the loads, the average weight of this design is taken as $170 \mathrm{~kg}$ per $\mathrm{m} 2$. Intensive landscaping of buildings involves planting shrubs, groups of flowers, and even dwarf trees on the cover, forming various architectural and landscape solutions for recreational areas. When calculating the loads from intensive landscaping, it is assumed to take the average load per $\mathrm{m} 2$ of $350 \mathrm{~kg}$. [22].

An important factor in the formation of a green cover is the selection of plants suitable for planting in the natural and climatic conditions of the region. At the moment, in the regulatory literature related to greening buildings there are "Recommendations for the designing of greening and landscaping of roofs of residential and public buildings and other artificial foundations" developed by Mosproject OJSC and can be applied to objects of the city of Moscow and the Moscow Region, this suggests the need to develop a similar document for the regions. In fig. 1, the differences in the climatic conditions of the regions are clearly expressed, therefore the plants described in the Recommendations should be supplemented in relation to the conditions of the Astrakhan region.

Based on the assessment of the status of existing green spaces in parks, squares, the main streets of the city of Astrakhan, conducted by scientists at the ASU, VLTU im. G.F. Morozov ,Moscow State University MV Lomonosov, as well as in the framework of scientific research at the Department of Architecture at NRU MGSU and a number of expeditions to the study region, it was found that in the green areas of the Moscow region 
mainly grow: linden, poplar, ash-tree maple, pencilvan ash, acutifolia maple, common lilac and mountain ash, etc., and in Astrakhan the following plants grow: pencilvan ash, boxwood, brilliant cotoneaster, red viburnum, euonymus, common mountain ash, small elm, white acacia and aylants, common maple Aries, hibiscus, etc. The predominant species is small-leaved elm, where its share in the total number of green spaces is $32.7 \%$. Researchers I.P. Kartasheva and E. N. Eliseeva recommend developing a set of measures aimed at selecting and planting tree-shrub and flower plants that are resistant to these conditions and the need for species diversity, and consider that "establishing a list of plants for each object, it is necessary to ensure that they in their biological properties and appearance, they corresponded to the climatic, soil, hydrological conditions of the area, the lighting regime, the purpose of landscaping, features of planning and development , architectural and artistic solution of the object "[10].

Therefore, on the basis of the studies, a list of plants was developed. It can be recommended for the formation of vegetation cover with horizontal landscaping of buildings of ethno cultural tourist clusters (Figure 3).

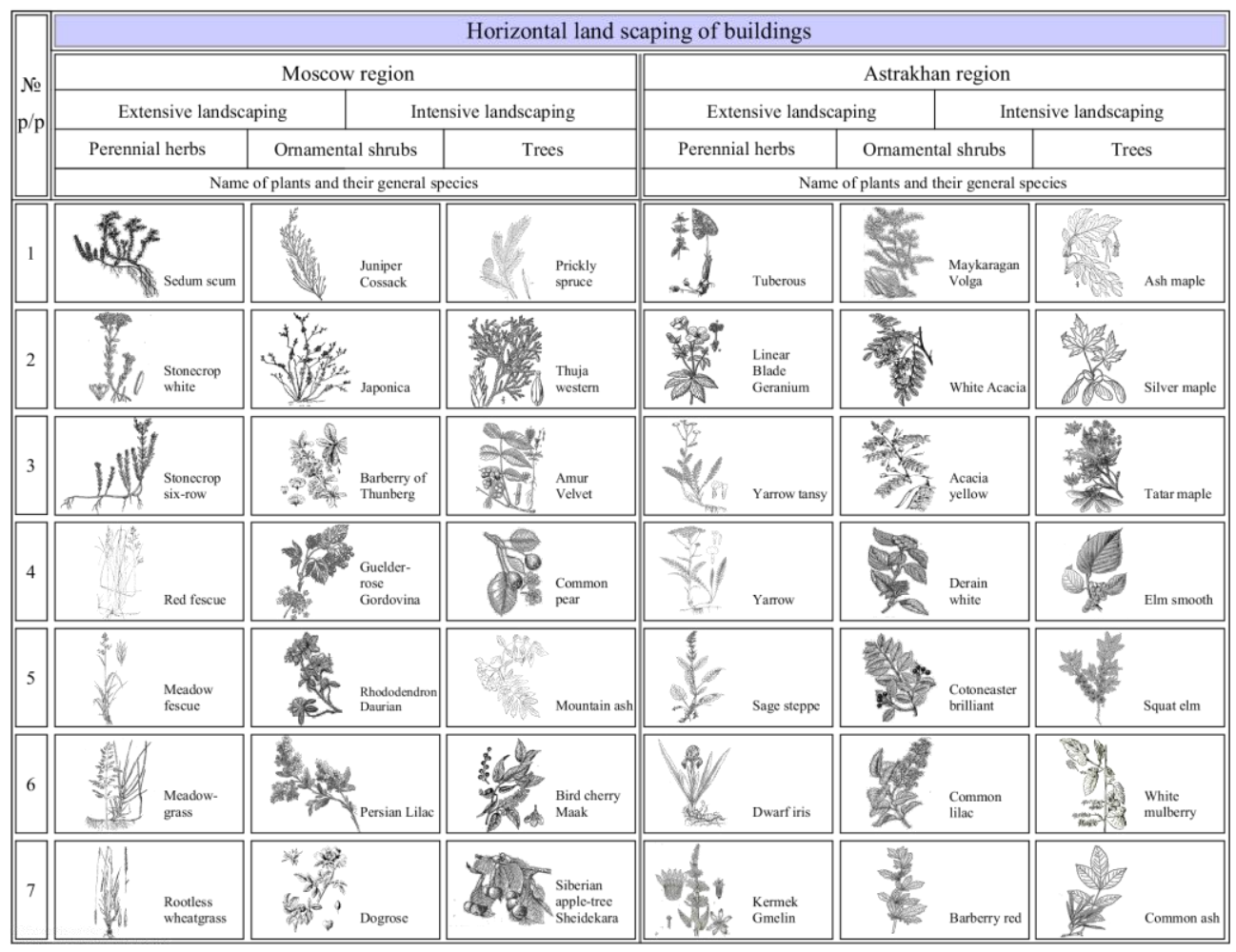

Fig. 3. Comparative analysis of plant species recommended for extensive and intensive horizontal landscaping of buildings of the ethno cultural tourism cluster in various regions of Russia.

These plants were selected based on their adaptive ability to climatic conditions characteristic of the Astrakhan region, consisting in high summer temperatures and low winter temperatures, lack of precipitation, high wind speed and resistance to traffic pollution in the city $[10,11,23]$. 


\section{Discussion}

These studies will contribute to the design and construction of sustainable "green" buildings of ethno-cultural tourism in the Astrakhan region.

\section{Conclusions}

Thus, in the process of creating an eco-architecture, the use of various methods of greening the environment using vertical and horizontal landscaping of buildings of ethnocultural tourist clusters in the Astrakhan region of the Russian-Kazakh border area contributes to the creation of a favorable microclimate in the premises, improved public health, increased employee productivity and reduced damage to nature this region, which suggests a qualitatively new character of interaction an ethnic settlement with a natural environment.

Our research was supported by the National Research Moscow State University of Civil Engineering, State University of Land Management, as well as Eurasian National University named after L.N. Gumilyov.

\section{References}

1. https://en.wikipedia.org/wiki/Astrakhan

2. A.A. Muhanalieva, O.V. Samsonova, P.D. Stoletova, Collection of articles of the XII International scientific-practical conference "Language and intercultural communication», 79-82 (2019)

3. Yu.A. Tabunshchikov, M.M. Brodatch, Ashrae journal 48(1), 26-31 (2006)

4. A.N. Tetior, European Journal of Natural History 5, 22-26 (2017)

5. S.V. Ilvitskaya, D.Yu. Ilvitsky, V.P. Etenko, T.V. Lobkova, Building materials 10, 6972 (2018) DOI:https://doi.org/10.31659/0585-430X-2018-764-10-69-72

6. S.V. Ilvitskaya, V.A. Lobkov, T.V. Lobkova, IOP Conference Series: Materials Science and Engineering 687, 055030 (2019) DOI: https://doi.org/10.1088/1757$899 \mathrm{x} / 687 / 5 / 055030$

7. O.L. Bancerova, Ecology, environment and conservation 23(1), 460-463 (2017)

8. O.L. Bancerova, MATEC Web of Conferences, 01034 (2017) DOI: https://doi.org/10.1051/matecconf/201710601034

9. S.V. Karetnikova, Industrial and civil construction 5, 14-19 (2019) DOI: https://doi.org/10.33622/0869-7019.2019.05.14-19

10. N.P. Kartashova, E.N. Eliseeva, Agro-industrial technologies of Central Russia 4(14), 102-109 (2019) DOI: https://doi.org/10.24888/2541-7835-2019-14-102-108

11. T.A. Fedorova, A.G. Stolyarova, P.S. Kordyukov, M.S. Osintseva, Vestnik RUDN. Series: Agronomy and Livestock 5, 105-111 (2013) DOI: https://doi.org/10.22363/2312-797x-2013-5-105-112

12. Unesco, https://en.unesco.org/

13. V.A. Lobkov, S.V. Ilvitskaya, T.V. Lobkova, International journal of applied sciences and technology INTEGRAL 2-2, 17 (2019) DOI:https://doi.org/10.24411/2658-35692019-12015

14. O.L. Bancerova, A.R. Kasimova, Journal of Environmental Management and Tourism 9.4(28), 771-776 (2018) DOI:https://doi.org/10.14505//jemt.v9.4(28).10 
15. V. Shuvalov, S.V. Ilvitskaya, IOP Conference Series: Materials Science and Engineering 365, $022026 \quad$ (2018) DOI: https://doi.org/10.1088/1757$899 \mathrm{x} / 365 / 2 / 022026$

16. R. Hindle, Studies in the History of Gardens \& Designed Landscapes 32(2), 99-110 (2012) DOI: https://doi.org/10.1080/14601176.2011.653535

17. S.V. Ilvitskaya, T.V. Lobkova, IOP Conference Series: Materials Science and Engineering, 012161 (2018) DOI: https://doi.org/10.1088/1757-899x/451/1/012161

18. Architecture Projects, https://www.archdaily.com/

19. N. Lekareva, A. Zaslavskaya, E3S Web of Conferences 33, 01010 (2017) DOI: https://doi.org/10.1051/e3sconf/20183301010

20. A.I. Khusnutdinova, O.P. Aleksandrova, A.N. Novik, Construction of Unique $\begin{array}{lllll}\text { Buildings and } & \text { 12(51), 20-32 (2016) DOI: }\end{array}$ https://doi.org/10.18720/CUBS.51.2

21. Vertical gardens Patrick Blank, https://www.verticalgardenpatrickblanc.com/

22. E.A. Dorozhkina, IOP Conference Series: Materials Science and Engineering 451, 012169 (2018) DOI: https://doi.org/10.1088/1757-899x/451/1/012169

23. A.L. Sal'nikov, V.N. Pilipenko, Russian Journal of Ecology 36(6), 383-390 (2005) DOI: https://doi.org/10.1007/s11184-005-0090-2 